\title{
Biomechanical Evaluation of a Novel Apatite-Wollastonite Ceramic Cage Design for Lumbar Interbody Fusion: A Finite Element Model Study
}

\author{
Celal Bozkurt $\mathbb{D}^{1},{ }^{1}$ Alpaslan Şenköylü, ${ }^{2}$ Erdem Aktaş, ${ }^{3}$ Baran Sarıkaya, ${ }^{1}$ Serkan Sipahioğlu, ${ }^{1}$ \\ Riza Gürbüz, ${ }^{4}$ and Muharrem Timuçin ${ }^{4}$ \\ ${ }^{1}$ Department of Orthopedics and Traumatology, Harran University School of Medicine, Osmanbey Kampusu, Mardin Yolu 20. Km, \\ Haliliye, 63190 Şanliurfa, Turkey \\ ${ }^{2}$ Department of Orthopaedics and Traumatology, Gazi University School of Medicine, Emniyet Mh Mevlana Bulvarı, Beşevler, \\ 06500 Ankara, Turkey \\ ${ }^{3}$ Saglık Bakanlıgı Ankara Eğitim ve Arastırma Hastanesi, Sukriye Mh. Ulucanlar Cd. No. 89, Altındag, 06340 Ankara, Turkey \\ ${ }^{4}$ Department of Metallurgical and Material Engineering, Middle East Technical University, Üniversiteler Eskisehir Yolu No. 1, Cankaya, \\ 06800 Ankara, Turkey
}

Correspondence should be addressed to Celal Bozkurt; bozkurt.celal@gmail.com

Received 12 August 2017; Revised 13 December 2017; Accepted 20 December 2017; Published 18 January 2018

Academic Editor: Radovan Zdero

Copyright (C) 2018 Celal Bozkurt et al. This is an open access article distributed under the Creative Commons Attribution License, which permits unrestricted use, distribution, and reproduction in any medium, provided the original work is properly cited.

Objectives. Cage design and material properties play a crucial role in the long-term results, since interbody fusions using intervertebral cages have become one of the basic procedures in spinal surgery. Our aim is to design a novel Apatite-Wollastonite interbody fusion cage and evaluate its biomechanical behavior in silico in a segmental spinal model. Materials and Methods. Mechanical properties for the Apatite-Wollastonite bioceramic cages were obtained by fitting finite element results to the experimental compression behavior of a cage prototype. The prototype was made from hydroxyapatite, pseudowollastonite, and frit by sintering. The elastic modulus of the material was found to be $32 \mathrm{GPa}$. Three intact lumbar vertebral segments were modelled with the ANSYS 12.0.1 software and this model was modified to simulate a Posterior Lumbar Interbody Fusion. Four cage designs in different geometries were analyzed in silico under axial loading, flexion, extension, and lateral bending. Results. The K2 design had the best overall biomechanical performance for the loads considered. Maximum cage stress recorded was $36.7 \mathrm{MPa}$ in compression after a flexion load, which was within the biomechanical limits of the cage. Conclusion. Biomechanical analyses suggest that K2 bioceramic cage is an optimal design and reveals essential material properties for a stable interbody fusion.

\section{Introduction}

Interbody fusions using intervertebral cages have become a basic procedure within spinal surgery to treat degenerative disc disease and spondylolisthesis. Interbody fusion cages restore disc height and also provide stability for functional spinal units [1]. Cage design and material both play crucial roles in long-term results. Many types of cages are available in the market, made from a variety of materials, including titanium, carbon fibre, and polyetheretherketone (PEEK) [2]. A few studies have reported that although the biomaterials that are used for the production of cages provide sufficient mechanical support, there is no direct osteointegration between the host bone and these materials; instead, a fibrous tissue forms between the cages and the host bone [3].

Apatite-Wollastonite $(\mathrm{A} / \mathrm{W})$ bioceramic composite is a bioactive and compatible material that is used for hardtissue repair. Its degradation rate is faster than that of hydroxyapatite (HA), which shows reduced solubility due to its chemical stability. The A/W bioceramic composite induces bone growth three times faster than HA [4-6]. Recent studies have concluded that direct osteointegration occurs between the host bone and the $\mathrm{A} / \mathrm{W}$ bioceramic composite material 
and that this connection increases with time [7]. In addition to this action, the ceramic-like composite also increases mineral concentration in adjacent tissues. Over time, as this bioceramic composite degrades and is replaced by bone, its mechanical support function gradually decreases [8].

Many clinical conditions of the spine can be simulated using the finite element method (FEM) to provide biomechanical insight into the construct and repair of the spine [9]. The advantage of FEM is that it can estimate the stresses within spinal ligaments, intervertebral discs, and other tissues related to the spine, which may be both technically difficult and time-consuming to do experimentally. Another benefit is the detailed motion analyses that can be utilized by this method. As a result, FEM investigators can ascertain the relationships and mechanisms between the implant and the related spinal segments. Because many different surgical procedures and treatment options can be simulated with FEM, only the most suitable implants need to be tested before the production process begins [10].

The research questions that this study seeks to answer are as follows: (1) Can we produce an $\mathrm{A} / \mathrm{W}$ bioceramic composite interbody fusion cage that is sufficiently robust to withstand various physiologic loading levels? (2) Do different cage geometries have a distinct effect on mechanical behavior (i.e., stress and strain)?

\section{Materials and Methods}

2.1. Production of $A / W$ Bioceramic Composite Cage. Our ceramic samples contain hydroxyapatite (47.5\%), pseudowollastonite (PW, 47.5\%), and frit (5\%; Sigma Aldrich Corp., USA). The HA powder was produced by the method developed by Akao et al. [12]. The wollastonite component of the ceramics was prepared via a thermal synthesis process. The product, identified by X-ray diffraction (XRD) as pseudowollastonite $(\alpha-\mathrm{CaSiO} 3)$, was milled to fine powder. The frit beads (Na2O-CaO-Al2O3-SiO2) were crushed and ground to a fineness below $3 \mu \mathrm{m}$ in size; prototype cages were then produced from this powder. The dimension of the cage produced was $15.5 \mathrm{~mm} \times 15.5 \mathrm{~mm} \times 10.2 \mathrm{~mm}$. The final geometry of the prototype cages was obtained via a Challenger 2412 Microcut machine.

2.2. Unprocessed Prototype Cage Biomechanical Test. A compression test was performed with an Instron testing machine and video extensiometry (Instron 5582 floor-mounted material testing system, Instron Products, USA) and an elastic modulus of the material was found; this test was then simulated with FEM. Two metal platens and the prototype cage were modelled for this purpose. The elastic modulus of the metal platens measured $200,000 \mathrm{~N} / \mathrm{mm}^{2}$, with a Poisson ratio of 0.3 . A 25,000 Newton $(25 \mathrm{kN})$ axial load was applied to the system (Figure 1).

2.3. FEM of the Intact Lumbar Vertebrae. The computerised tomography (CT), magnetic resonance imaging (MRI), and colour sections of a male cadaver which may be found in the Visible Human Project (National Library of Medicine,

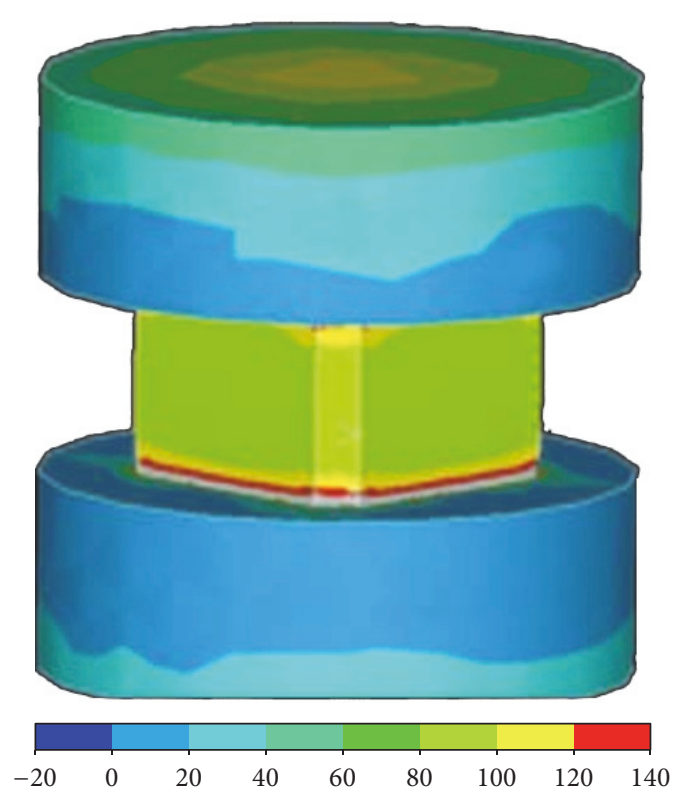

Figure 1: Two metal platens and the prototype cage modelled to perform a compression test with an Instron testing machine and video extensiometry.

National Institutes of Health, USA) database were converted to a surface model by the use of 3D-Doctor 3.5.050106 software (Able Software, USA). The surface model was then converted to a solid model using Autodesk AutoCAD 2005 (Autodesk, Inc., USA).

The solid model was then transferred to Ansys 12.0.1 (Ansys Inc., USA). The model included vertebral bones, intervertebral disks, end plates, posterior elements, and ligaments (supraspinous, interspinous, transverse, posterior longitudinal, anterior longitudinal, and flavum). The material properties were assumed to be homogenous and isotropic; the mechanical data were gathered from the literature [11] (Table 1).

The ligaments were modelled as two-point elements that were resistant to all but distraction. Their anatomic locations and cross-sectional areas were in concordance with the literature [11].

The surface-to-surface frictional areas between biological tissues were simulated assuming a friction coefficient of 0.1 ; the distance between the facet joint surfaces was assumed to be $0.5 \mathrm{~mm}$. The connections of the rods to the pedicle screws were assumed to be rigid. The diameters of the rods and screws (made of titanium) were assumed to be $6 \mathrm{~mm}$.

The intact model was comprised of 77,282 nodes and 48,172 elements. The instrumented models' node and element numbers changed according to the geometry of the cages. The instrumented models were comprised of 102,000 nodes and 59,000 elements on average.

2.4. FEM of the Lumbar Interbody Fusion Model. Bilateral facetectomy and partial discectomy were performed in the L4-L5 motion segment to simulate posterolateral interbody 
TABLE 1: Material properties of the tissues within the spinal column [11]. ALL: anterior longitudinal ligament; PLL: posterior longitudinal ligament; TL: transverse ligament; LF: ligamentum flavum; ISL: interspinous ligament; SSL: supraspinous ligament; CL: capsular ligament.

\begin{tabular}{lccc}
\hline Material & Elastic modulus & Poisson coefficient & Cross-sectional area \\
\hline Cortical bone & 12000 & 0.3 & - \\
Cancellous bone & 100 & 0.2 & - \\
Posterior elements & 3500 & 0.25 & \\
Intervertebral disc & & 0.499 & 0.45 \\
$\quad$ Nucleus & 1 & - & 0.76 \\
Ground substance & 4.2 & 0.4 & 63,7 \\
Annulus fibers & 450 & & 20 \\
End plate & 24 & - & 3.6 \\
Ligaments & & - & 40 \\
ALL & 20 & - & 40 \\
PLL & 20 & - & 30 \\
TL & 58.7 & - & 60 \\
LF & 19.5 & - & - \\
ISL & 11.6 & 0.28 & \\
SSL & 15 & 32.9 & \\
KL & 110000 & & \\
Titanium & & & \\
\hline
\end{tabular}

fusion (PLIF); cages and a posterior instrumentation system were then implanted. Four pedicle screws $(r=6 \mathrm{~mm})$ were implanted into the L4 and L5 lumbar vertebrae. Screws were connected with two rods $(r=6 \mathrm{~mm})$. The screws and rods were modelled with beam elements. Two cages were placed into the intervertebral space. A postoperative bone-cage interface was then modelled using surface-to-surface contact elements. These contact elements were defined to transfer only compressive forces; they did not transfer distraction forces. The interface friction coefficient between implant and bone was assumed to be 0.8 , in accordance with the literature (Figure 2).

Cages must be able to withstand biomechanical loads and must also leave enough space to place a bone graft for fusion. Four different cage geometries (illustrated in Figure 3) were designed and evaluated with FEM.

Twenty-node solid elements were then used to model the cortical bone, cancellous bone, end plate, and intervertebral disc. Annulus fibrosis was formed by layers that were placed at a $30^{\circ}$ angle to one another and that only reacted against distraction. These layers were embedded into ground substance; there were seven layers. A reinforcement element model of the Ansys software was used to define these layers.

The facet joints were modelled as nonlinear contact surfaces:

(1) $\mathrm{K} 1$ had an $8 \mathrm{~mm}$ in diameter cylindrical hall between the upper and lower surfaces.

(2) $\mathrm{K} 2$ had two $6 \mathrm{~mm}$ in diameter cylindrical halls on each side of the cage.

(3) $\mathrm{K} 3 \mathrm{had}$ two $6 \mathrm{~mm}$ in diameter cylindrical halls on each side, and a $3 \mathrm{~mm}$ in diameter cylindrical hall between the upper and lower surfaces.

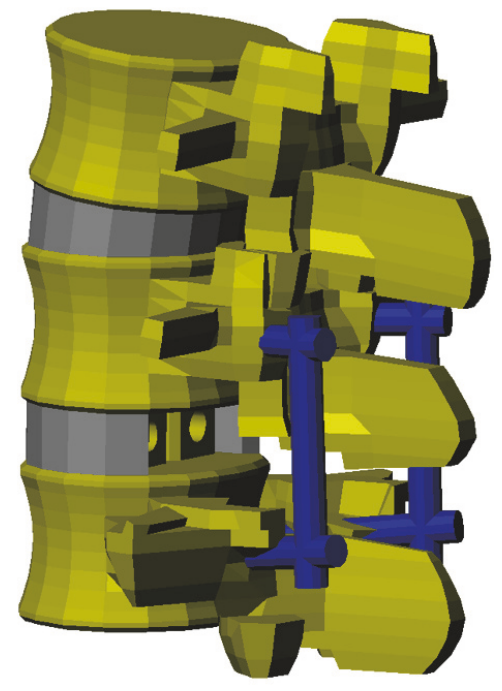

FIGURE 2: Following bilateral facetectomy and partial discectomy performed in silico in the L4-L5 motion segment to simulate posterolateral interbody fusion (PLIF), cages and a posterior instrumentation system are implanted.

(4) $\mathrm{K} 4$ had four $2 \mathrm{~mm}$ in diameter cylindrical halls between the upper and lower surfaces.

The base of the L5 vertebra was fixed in every degree of freedom. Loadings were taken from the literature [9]. A $400 \mathrm{~N}$ axial compression and $6 \mathrm{Nm}$ bending moment were separately applied, and Von Mises stress distributions were computed for the L4-L5 motion segment.

Biomechanical tests on the processed prototype cage were performed with an Instron testing machine; these tests were 


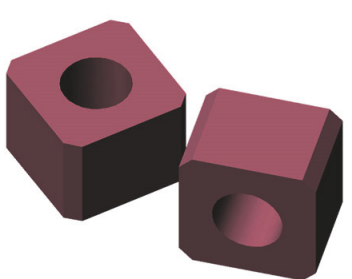

K1

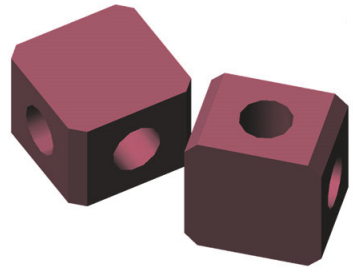

K2

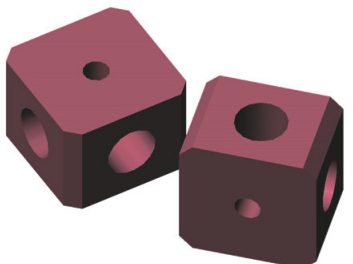

K3

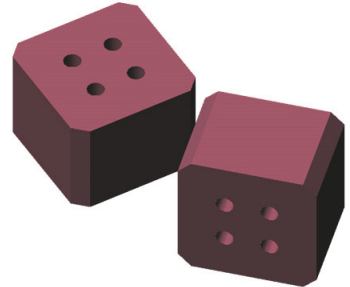

K4

FIGURE 3: Illustration of the four different cage geometries designed and evaluated with FEM (finite element modelling).

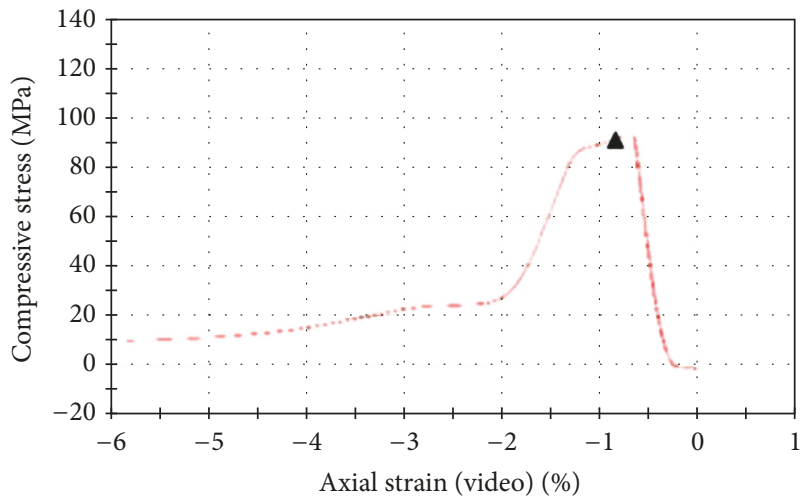

FIGURE 4: Elastic modulus of the ceramic cage being calculated after the compression test of the prototype cage.

simulated with FEM. Two metal platens and the cage were modelled for this purpose. A 5,000 N (5 kN) axial load was applied to the system in FEM.

\section{Results}

3.1. Prototype Cage Biomechanical Test. An elastic modulus of the ceramic cage was calculated as $32 \mathrm{GPa}$ after the compression test of the prototype cage; the maximum compressive stress value was $121.16 \mathrm{MPa}$. Before the failure of the unprocessed cage, the maximum load had been $29.1 \mathrm{kN}$ (Figure 4).

The prototype cage was loaded to $25 \mathrm{kN}$ in the FEM; the maximum compression value was $244.0 \mathrm{MPa}$. When the Von Mises graphics were analyzed, these high values (which exceeded the mechanical capacity) could be observed on the surfaces in a small area. Most of the compression values were between 80 and $100 \mathrm{MPa}$. These results were similar to those of the real compression test results (Figure 5).

3.2. Evaluation of the Cage Geometries with FEM. The maximum stress values and localisations were evaluated; the models included a nonimplanted intact model and four implanted models, using the cage geometries of $\mathrm{K} 1, \mathrm{~K} 2, \mathrm{~K} 3$, and $\mathrm{K} 4$.

In the intact model, the maximum stress values viewed during flexion, bending, and rotation were found at the intervertebral disc space; during extension, maximum stress

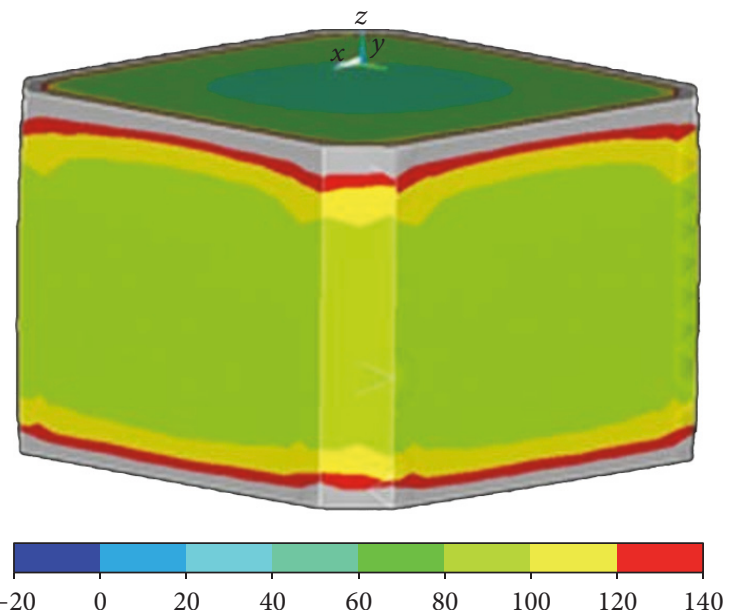

Figure 5: Prototype cage loaded to $25 \mathrm{kN}$ in the FEM. High compression values that exceeded the mechanical capacity were observed on the surfaces within a small area.

value was in the posterior elements. The maximum stress value was 101.4 MPa.

The maximum stresses in $\mathrm{K} 1$ and $\mathrm{K} 3$ were observed at the intervertebral space for all modes of loading; the stress values were higher compared to the intact model for all loadings except extension. The maximum stress values observed in K1 and $\mathrm{K} 3$ were $112.1 \mathrm{MPa}$ and $114.6 \mathrm{MPa}$, respectively (Figure 6).

In the $\mathrm{K} 2$ model, the maximum stress values in all modes of loading were observed in the posterior elements and in the posterior instrumentation system. All stress values were found to be lower compared to the intact model. The maximum stress value (63.6 $\mathrm{MPa})$ was observed during rotation (Table 2).

In the $\mathrm{K} 4$ model, the maximum stress values were observed on the posterior elements and the posterior instrumentation system, except with bending, where the maximum stress was observed at the intervertebral disc space. All stress values were found to be lower compared to the intact model. The maximum stress value was observed during rotation, at 63.2 MPa (Table 2).

3.3. L5 End Plate Compression. The L5 end plate stress distribution was similar to that of the intact model for flexion, extension, and rotation. But for bending, the stress values on the L5 end plate were observed to be significantly higher in all 
TABLE 2: Maximum stress values of the whole construct and their localisations under different loads. The maximum stress values of the whole construct by using K2 and K4 designs were significantly better $(p<0.05)$. I: intact model.

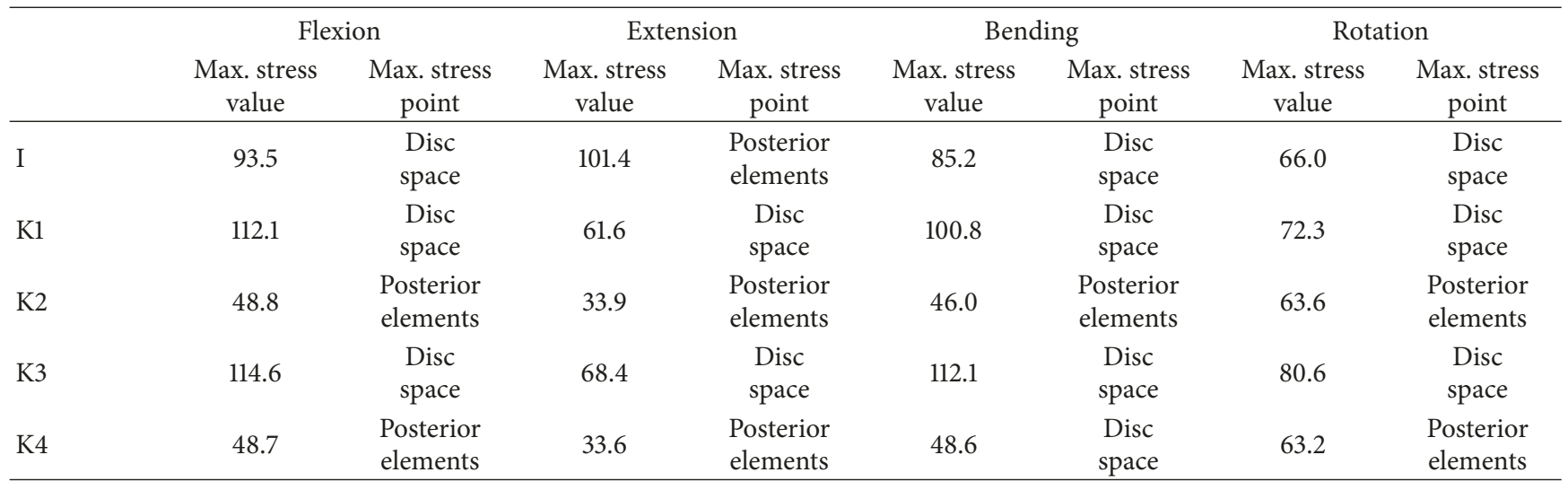

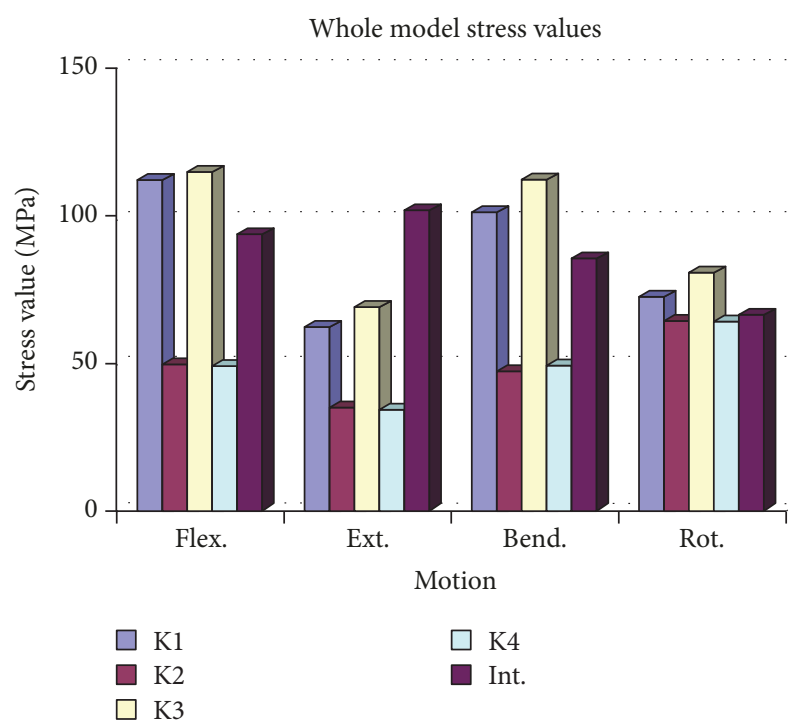

FIGURE 6: For all modes of loading, maximum stresses in $\mathrm{K} 1$ and $\mathrm{K} 3$ were observed at the intervertebral space.

models. The maximum L5 end plate stress value (29.3 MPa) was observed in the $\mathrm{K} 4$ model during bending, while the minimum L5 end plate stress value (14.2 MPa) was observed in the $\mathrm{K} 2$ model during extension (Figure 7 and Table 3 ).

3.4. Cage Compression. In all loadings, the maximum stress values of the cages were significantly higher in the $\mathrm{K} 1$ and $\mathrm{K} 3$ models compared to K2 and K4. Among all models, the minimum stress values were observed in the $\mathrm{K} 2$ model for all loadings. The flexion and bending stress values were found to be higher than extension and rotation in the $\mathrm{K} 2$ model (Figure 8 and Table 4).

3.5. Biomechanical Test of the Processed Cage. Compression tests were conducted with the processed cage; failure was observed at $4.3 \mathrm{kN}$ for the first sample, $3.9 \mathrm{kN}$ for the second sample, and $5.6 \mathrm{kN}$ for the third sample, for an average of $4.6 \mathrm{kN}$.

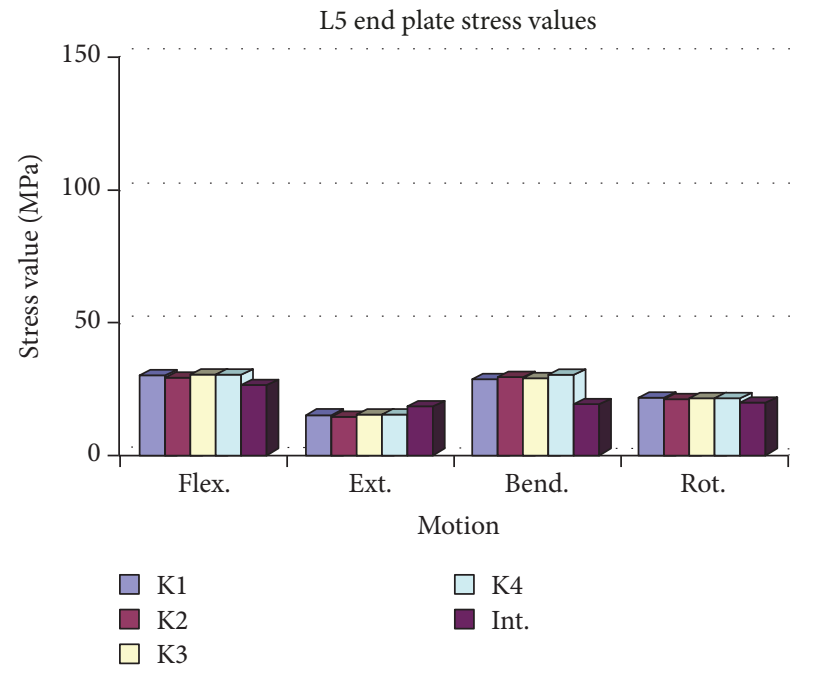

FIGURE 7: The L5 end plate stress distribution was similar to that of the intact model for flexion, extension, and rotation. The maximum L5 end plate stress value (29.3 MPa) was observed in the K4 model during bending.

A $5 \mathrm{kN}$ axial compressive loading was applied to the cage, and the Von Mises stresses were analyzed. Stress values were found to be higher at the inner sides and at the corners. The maximum stress at the inner site was $209.4 \mathrm{MPa}$. The stress values at the processed inner sites were at $80-100 \mathrm{MPa}$ intervals.

\section{Discussion}

At $29.1 \mathrm{kN}$ axial loading, a $121.16 \mathrm{MPa}$ maximum compression stress was experimentally estimated on the prototype cage before failure. An FEM compression test simulation was conducted with the prototype cage, and a maximum axial load of $25 \mathrm{kN}$ was applied. A few small areas exceeded $100 \mathrm{MPa}$, and the maximum compression stress was found to be $244 \mathrm{MPa}$ but only on the surface of the cage. This high value would appear to be an artefact that was due to 
TABLE 3: Maximum stress values in the L5 end plate and their localisations under different loads. There were no significant differences between cage designs $(p>0.05)$. I: intact model.

\begin{tabular}{lcccccccc}
\hline & \multicolumn{2}{c}{ Flexion } & \multicolumn{2}{c}{ Extension } & \multicolumn{2}{c}{ Bending } & \multicolumn{2}{c}{ Rotation } \\
& $\begin{array}{c}\text { Max. stress } \\
\text { value }\end{array}$ & $\begin{array}{c}\text { Max. stress } \\
\text { point }\end{array}$ & $\begin{array}{c}\text { Max. stress } \\
\text { value }\end{array}$ & $\begin{array}{c}\text { Max. stress } \\
\text { point }\end{array}$ & $\begin{array}{c}\text { Max. stress } \\
\text { value }\end{array}$ & $\begin{array}{c}\text { Max. stress } \\
\text { point }\end{array}$ & $\begin{array}{c}\text { Max. stress } \\
\text { value }\end{array}$ & $\begin{array}{c}\text { Max. stress } \\
\text { point }\end{array}$ \\
\hline I & 25.9 & Anterior & 17.1 & Posterior & 17.7 & Anterolateral & 18.4 & Anterior \\
K1 & 28.9 & Anterior & 14.7 & Anterior & 27.9 & Anterolateral & 20.5 & Anterior \\
K2 & 28.0 & Anterior & 14.2 & Anterior & 28.9 & Anterolateral & 20.0 & Anterior \\
K3 & 29.0 & Anterior & 14.8 & Anterior & 27.9 & Anterolateral & 20.5 & Anterior \\
K4 & 28.9 & Anterior & 14.6 & Anterior & 29.3 & Anterolateral & 20.5 & Anterior \\
\hline
\end{tabular}

TABLE 4: Maximum stress values of the different cage designs. The stress values were significantly lower in the K2 design $(p<0.05)$.

\begin{tabular}{lcccccccc}
\hline & \multicolumn{2}{c}{ Flexion } & \multicolumn{2}{c}{ Extension } & \multicolumn{2}{c}{ Bending } & \multicolumn{2}{c}{ Rotation } \\
& $\begin{array}{c}\text { Max. } \\
\text { stress value }\end{array}$ & $\begin{array}{c}\text { Max. } \\
\text { stress point }\end{array}$ & $\begin{array}{c}\text { Max. } \\
\text { stress value }\end{array}$ & $\begin{array}{c}\text { Max. } \\
\text { stress point }\end{array}$ & $\begin{array}{c}\text { Max. } \\
\text { stress value }\end{array}$ & $\begin{array}{c}\text { Max. } \\
\text { stress point }\end{array}$ & $\begin{array}{c}\text { Max. } \\
\text { stress value }\end{array}$ & stress point \\
\hline K1 & 112.1 & Anterior & 61.6 & Posterior & 100.8 & Anterolateral & 72.3 & Anterior \\
K2 & 32.6 & Anterior & 15.3 & Posterior & 33.7 & Anterolateral & 24.3 & Anterior \\
K3 & 114.6 & Anterior & 68.4 & Posterior & 112.1 & Anterolateral & 80.6 & Anterior \\
K4 & 46.3 & Anterior & 20.2 & Anterior & 48.6 & Anterolateral & 36.8 & Anterior \\
\hline
\end{tabular}

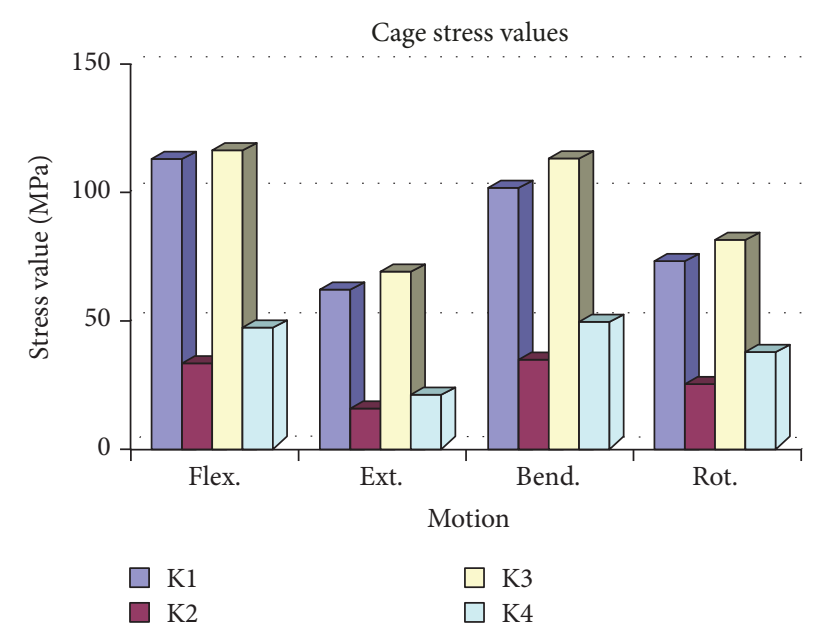

FIGURE 8: Compared to K2 and K4, maximum stress values of the cages were significantly higher in the $\mathrm{K} 1$ and $\mathrm{K} 3$ models. The K2 model revealed minimum stress values during all loadings.

modelling assumptions and idealizations at the boundary. The compression stress values of the cage were generally computed to be within an 80-100 MPa interval. According to this analysis (and from our observations from the real compression test), we conclude that failure of the cage will result just above $25 \mathrm{kN}$, as stress levels at all areas approximate to $29.1 \mathrm{kN}$. Consistency between the experimental tests that were achieved and the FEM simulations provide confidence that the cage model is indeed realistic.

In an FEM study, Zhong et al. employed topology optimization to design a new cage from an existing titanium cage. They compared the novel cage with the existing cage.
After comparison, they designed a new cage that had similar biomechanical performance and more space for bone graft [13].

Our analysis of the $\mathrm{K} 1$ and $\mathrm{K} 3$ models revealed that stress distribution condensed at the intervertebral space on the cages.

In the $\mathrm{K} 2$ model, maximum stress values in all modes of loading were observed on the posterior elements and in the posterior instrumentation system. The maximum stress values detected on the cages were significantly lower than in the intact model. In all compression models and all modes of loading, stress values were detected to be significantly lower than in the $\mathrm{K} 1$ and $\mathrm{K} 3$ model. These stress levels were within the range of biomechanical performance that would be acceptable for the A/W bioceramic composite. The K2 model demonstrated that the posterior elements and the posterior instruments were effective in load sharing and decreased the loads on the cages; thus, increased loading at the anterior compartment of the spine could enhance fusion. Although the stress values of the $\mathrm{K} 2$ and $\mathrm{K} 4$ models were computed to be similar, the values of the K4 model were minimally higher compared to the K2 model.

In addition to adequate biomechanical performance, an ideal cage design should have enough space for bone grafting. In the current study, the best biomechanical performance was computed in the $\mathrm{K} 2$ model. It should also be noted that there was enough space for a bone graft in this model. Similar to $\mathrm{K} 3$, by drilling an extra hole in the upper surface of the K2 model, the space for a bone graft was widened. Hence, this alteration significantly led to increased stress.

Similarly, in the K1 model, the hole in the upper surface significantly increased the stress values. In order to avoid this problem, the dimension of the hole might be decreased, but this could lead to narrowing of the space for the graft. 
The K4 model was found to be biomechanically inferior to the K2 model; the space available inside the K4 model was also narrower than in $\mathrm{K} 2$.

In an FEM study, Vadapalli et al. compared titanium and PEEK cages and found that the stress values of vertebrae end plates for titanium cages were 2.5 times higher than for PEEK cages; they concluded that maximum stress values (48 MPa for the titanium cage and $20 \mathrm{MPa}$ for the PEEK cage) were observed during a bending load [11]. In the current bioceramic composite cage study, the maximum end plate stress value was detected (at 28.9 MPa) under the same bending load. This value was minimally higher than the value of the PEEK cage but was significantly lower than that of the titanium cage. Therefore the $\mathrm{A} / \mathrm{W}$ bioceramic composite cage shows similar risk to the PEEK cage (and significantly lower risk than the titanium cage) for end plate fracture formation.

Interbody cages are generally used with posterior instrumentation systems; in clinical procedures, posterior instrument failures are observed more than cage failures [14]. In another FEM study, Zhong et al. used a titanium cage and subjected the lumbar spine to $10 \mathrm{Nm}$ flexion, extension, torsion, and lateral bending moment with $150 \mathrm{~N}$ axial preload. At these loading conditions, the stress values on the posterior instruments in flexion, extension, bending, and rotation were 73.4 MPa, 61 MPa, 77.3 MPa, and 96.1 MPa, respectively. In the current study, the K2 model's axial preload was $400 \mathrm{~N}$, and the moment was $6 \mathrm{Nm}$ for each mode of loading. The stress values on the posterior instruments on flexion, extension, bending, and rotation were $48.8 \mathrm{MPa}$, 33.9 $\mathrm{MPa}, 46 \mathrm{MPa}$, and 63.6 $\mathrm{MPa}$, respectively. Compared to the current study, the loading conditions were different in Zhong et al.s study in terms of higher moment and lower axial preload. Although the loading conditions were different in the aforementioned two studies, the stress values that were compared in the posterior elements turned out to be lower in the K2 model. These data suggest that the A/W bioceramic composite cage can carry enough load at the anterior part of the spine and can support stabilization well.

After the compression of the three processed cages, the mean failure value was $4.6 \mathrm{kN}$ in the axial loading. We believe that the different biomechanical performances may have been due to microfractures that had occurred during the cage process. These differences will not be observed if these cages are fabricated via moulding.

A K2 cage compression test was also simulated with FEM. In this test, the axial load applied was $5 \mathrm{kN}$, which was close to the mean value $(4.6 \mathrm{kN})$ of the real test. The stress values were in the range of $80-100 \mathrm{MPa}$ at the centre. We thought that, by increasing the axial load, the stress would have increased and we would have observed the failure of the cage. A comparison between the real test and the FEM test found that they were concordant. Although the FE model that was used in the current study utilized literaturederived material properties, the main limitation of our study is that experimental validation of the FEM is lacking. Another limitation of our study is not to perform cycling loading and impact tests to define the material properties of $\mathrm{A} / \mathrm{W}$ bioceramic. Our aim was to produce a prototype A/W bioceramic cage for spinal fusion. For this purpose, we tested A/W bioceramic cage with FEM. However, in order to define the material properties and validate the FEM, we only performed biomechanical compression tests. We would conduct advanced biomechanical analyses including cyclic loading and impact tests in the future studies.

In conclusion, the FEM simulation has the advantage of demonstrating the relationship and mechanism between implant and related spinal segments. The A/W bioceramic composite is a bioactive and compatible material that can effectively be used for interbody fusion. We must also keep in mind that the design of the cage plays a crucial role (in addition to its material properties) for achieving stable fusion. Although the K2 bioceramic composite cage model was found to have favorable biomechanical performance, animal studies must be conducted to elucidate the optimal and final design for this cage.

\section{Ethical Approval}

Our study is a biomechanical and FEM study. So there was no need for the approval of an ethical committee.

\section{Conflicts of Interest}

The authors declare that they have no conflicts of interest.

\section{Acknowledgments}

The authors would like to thank Emir Birant for preparing the FEM simulations. Support for this research has been provided by the Gazi University Scientific Research Fund and Turkish Society of Orthopaedic Surgery and Traumatology.

\section{References}

[1] S. L. Blumenthal and D. D. Ohnmeiss, "Intervertebral cages for degenerative spinal diseases," The Spine Journal, vol. 3, no. 4, pp. 301-309, 2003.

[2] S. M. Kurtz and J. N. Devine, "PEEK biomaterials in trauma, orthopedic, and spinal implants," Biomaterials, vol. 28, no. 32, pp. 4845-4869, 2007.

[3] Y. Hojo, Y. Kotani, M. Ito et al., "A biomechanical and histological evaluation of a bioresorbable lumbar interbody fusion cage," Biomaterials, vol. 26, no. 15, pp. 2643-2651, 2005.

[4] M. Amaral, M. A. Costa, M. A. Lopes, R. F. Silva, J. D. Santos, and M. H. Fernandes, "Si3N4-bioglass composites stimulate the proliferation of MG63 osteoblast-like cells and support the osteogenic differentiation of human bone marrow cells," Biomaterials, vol. 23, no. 24, pp. 4897-4906, 2002.

[5] M. Bosetti and M. Cannas, "The effect of bioactive glasses on bone marrow stromal cells differentiation," Biomaterials, vol. 26, no. 18, pp. 3873-3879, 2005.

[6] Y. Fujishiro, L. L. Hench, and H. Oonishi, "Quantitative rates of in vivo bone generation for Bioglass and hydroxyapatite particles as bone graft substitute," J Mater Sci Mater Med, vol. 8, no. 11, pp. 649-652, Nov 1997.

[7] S. Mistry, D. Kundu, S. Datta, and D. Basu, "Effects of bioactive glass, hydroxyapatite and bioactive glass-Hydroxyapatite composite graft particles in the treatment of infrabony defects," 
Journal of Indian Society of Periodontology, vol. 16, no. 2, pp. 241246, 2012.

[8] E. Schepers, M. D. Clercq, P. Ducheyne, and R. Kempeneers, "Bioactive glass particulate material as a filler for bone lesions," Journal of Oral Rehabilitation, vol. 18, no. 5, pp. 439-452, 1991.

[9] L. G. Gilbertson, V. K. Goel, W. Z. Kong, and J. D. Clausen, "Finite Element Methods in Spine Biomechanics Research," Critical Reviews in Biomedical Engineering, vol. 23, no. 5-6, pp. 411-473, 1995.

[10] Q. H. Zhang and E. C. Teo, "Finite element application in implant research for treatment of lumbar degenerative disc disease," Medical Engineering \& Physics, vol. 30, no. 10, pp. 12461256, 2008.

[11] S. Vadapalli, K. Sairyo, V. K. Goel et al., "Biomechanical rationale for using polyetheretherketone (PEEK) spacers for lumbar interbody fusion-a finite element study," The Spine Journal, vol. 31, no. 26, pp. E992-E998, 2006.

[12] M. Akao, H. Aoki, and K. Kato, "Mechanical properties of sintered hydroxyapatite for prosthetic applications," Journal of Materials Science, vol. 16, no. 3, pp. 809-812, 1981.

[13] Z.-C. Zhong, S.-H. Wei, J.-P. Wang, C.-K. Feng, C.-S. Chen, and C.-H. Yu, "Finite element analysis of the lumbar spine with a new cage using a topology optimization method," Medical Engineering \& Physics, vol. 28, no. 1, pp. 90-98, 2006.

[14] K. R. Eck, K. H. Bridwell, F. F. Ungacta, M. A. Lapp, L. G. Lenke, and K. Daniel Riew, "Analysis of titanium mesh cages in adults with minimum two-year follow-up," The Spine Journal, vol. 25, no. 18, pp. 2407-2415, 2000. 


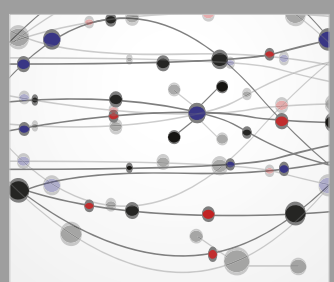

The Scientific World Journal
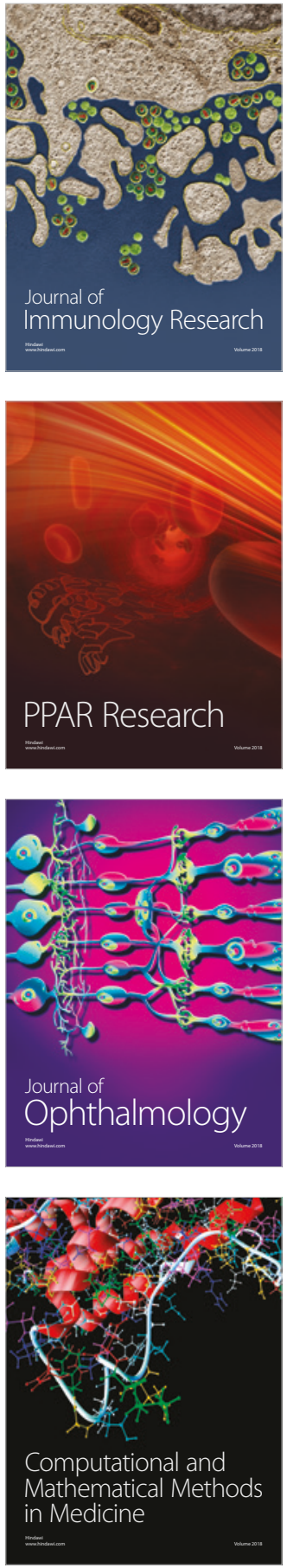

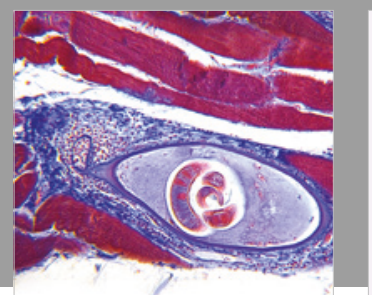

Gastroenterology Research and Practice

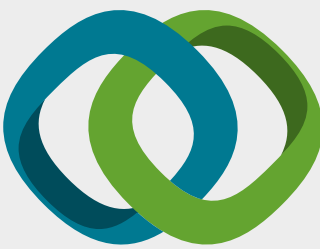

\section{Hindawi}

Submit your manuscripts at

www.hindawi.com
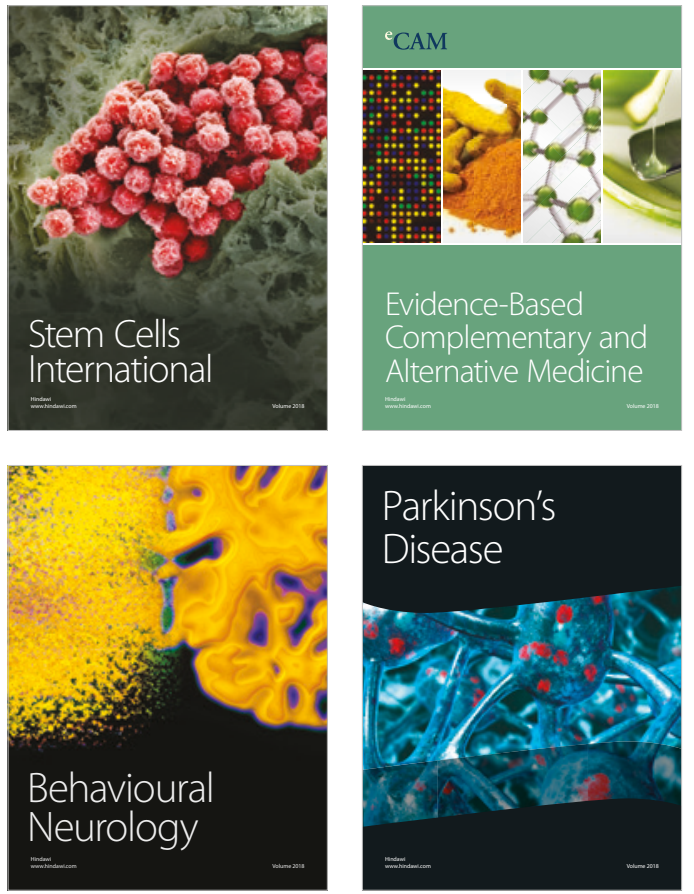

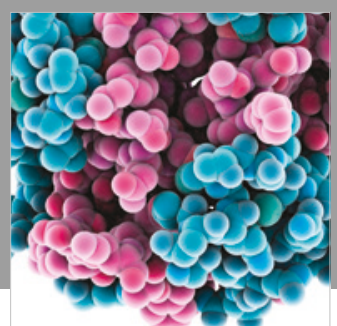

ournal of

Diabetes Research

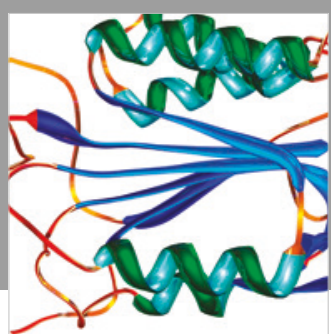

Disease Markers
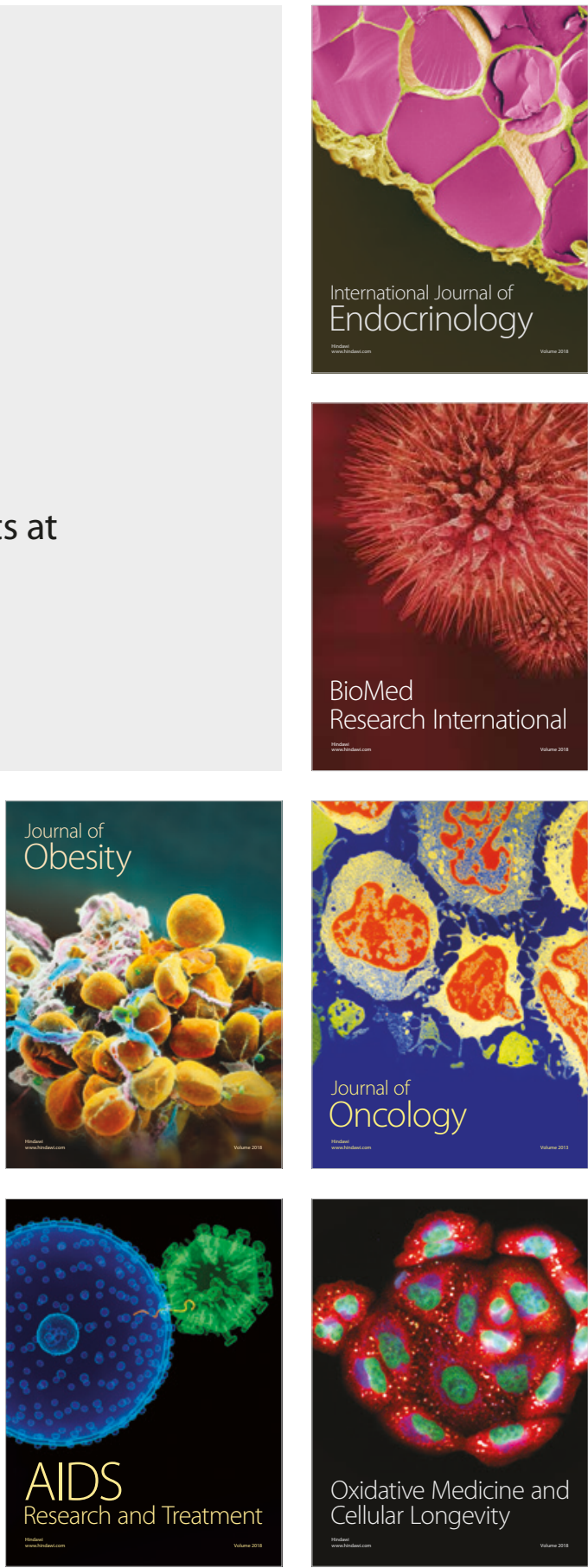